(Edició cura de) M. Dolors MADREnAs: Va de broma? Aproximació a la paròdia literària, Barcelona: Edicions 62, El cangur plus, 276, 1999.

\title{
CONCEPTO DEL LIBRO. PARTES
}

"El cangur plus" es una iniciativa editorial que pretende dar a los lectores de la colección "El cangur" una oportunidad de profundizar, jugar o aprender a partir de unos textos. Estos lectores no tienen que ser forzosamente escolares, sino más bien un público interesado, aunque no especializado. Por eso, al presentar las actividades a realizar sobre los textos, no se habla de "Propostes didàctiques", sino de "Per llegir millor". Cada título, pues, pretende crear un vínculo con el lector más allá de la simple lectura. "El cangur plus"puede recoger textos únicos de un solo autor, o bien puede partir de antologías, como es el caso que nos ocupa.

Va de broma? se estructura en cinco grandes apartados, más una introducción. El I y el II van referidos, respectivamente, al Quijote y a la "Narrativa i altres proses". El III se dedica a la poesía, el IV al teatro y el V, "De tot una mica". Una bibliografía única reúne textos de creación antologados y textos de crítica mencionados o consultados. Sin embargo, una segunda lectura nos puede llevar a una segunda distribución del esquema del libro, que coexiste con la anterior, y que dividiría el libro en tres partes 1) las observaciones teórico-críticas de la autora, 2), los textos literarios antologados, y 3 ) el desarrollo didáctico.

La mayor parte de las aportaciones teóricas de la autora se concentran en la introducción. D. Madrenas, a tenor del público a quien va dirigido el libro, se ve en la dificultosa tarea de dar una definición simple y concisa de parodia, tarea harto difícil a la que renuncia. Más bien lo que pretende es poner en evi- 
dencia la maraña conceptual y semántica en la que se ve envuelto el término, y los deslizamientos que sufre hacia denominaciones como sátira o ironía, por no hablar de otros (pastiche o travestimiento).

Para no perderse en este piélago, D. Madrenas establece dos líneas de análisis: una, la relación entre la parodia y su modelo, y dos, la caracterización de la parodia como concepto literario.

En la primera línea, la autora define la parodia como la relación que se da entre un modelo que un autor quiere imitar de manera explícita y la discordancia que en mayor o menor grado pretende establecer en su nueva creación a fin de conseguir diferentes efectos en el lector. Por supuesto, uno de los efectos fundamentales es el de la comicidad, el humor, pero no sólo eso: la mayoría de parodias indican, al mismo tiempo, una posición crítica o la presencia de un nuevo sitema de valores que marca las diferencias con respecto al modelo original. Hay, además, que tener en cuenta el uso de la palabra "parodia" para denominar textos en los que se establece la relación similar con el modelo, pero en los que está ausente cualquier deseo de provocar una reacción crítica o cómica. Se trata de las recreaciones, homenajes a textos anteriores, que D. Madrenas ejemplifica con Caperucita en Manhattan, de C. Martín Gaite.

Con respecto a la naturaleza del modelo, D. Madrenas afirma que "Si bé el model ha de ser textualment visible, no ha de d'ésser específicament literari, en aquests casos, però, ha de posseir una identitat ferma i peculiar, ser un material convencional el llenguatge i/o l'estructura del qual ha d'estar codificat (esquemes estandaritzats en la tradició literària), o, si més no, conservar uns mínims referents que el facin identificable" (pág. 14). La naturaleza del modelo es una nueva dificultad para conseguir una diferenciación entre sátira y parodia: para algunos críticos, recuerda la autora, el modelo de la sátira es extraliterario, mientras que en la parodia sería siempre literario.Ahora bien, como se nos dice más adelante, el modelo literario no tiene por qué circunscribirse a una obra concreta: puede dirigirse, también, a otros elementos temáticos, formales, genéricos o históricos. Así, se puede parodiar un topos o un arquetipo determinado, un tropo o forma de discurso, todo un género o bien un movimiento histórico literario.

Esta amplitud de posibilidades nos lleva al segundo nivel de análisis: el de la caracterización de la parodia como concepto literario. D. Madrenas, siguiendo a Claudio Guillén, opta por considerar la parodia como una modalidad; es decir una categoría a caballo entre los géneros y las formas. Esta posición explica que no la considere un género aparte, $y$, por el contrario, que detecte su presencia en diversos grandes géneros -opción que tomará para ordenar su antología- . Al mismo tiempo, la autora se interroga sobre la función de la parodia como recurso, es decir, conjunto de procedimientos de distorsión al servicio de otras intenciones textuales. Más adelante presenta algunos de estos recursos, tanto los que pueden afectar al tema, a los personajes o al sentido general. 
Cabe destacar varios aspectos muy interesantes en la presentación teórica: D. Madrenas no cae en la tentación simplista de dar unas definiciones estrictas y limitadoras sino que alerta al público lector- un público no especializadosobre las complejidades de delimitación de este concepto. Pero le da pistas para ver los posibles alcances de este universo. El lector de este libro, pues, tiene suficientes elementos para enfrentarse a la antología que sigue, y, al mismo tiempo, tiene caminos abiertos poder profundizar en la delimitación de los conceptos. Otra tentación evitada es la de abrazar una única escuela crítica para presentar el concepto de parodia: así la línea de un Genette - tan usada y abusada en los últimos tiempos- se combina con la crítica anglosajona, sin descuidar el origen histórico de los conceptos literarios, deudores de la retórica clásica. Y, por último, un acierto constante es la sensatez literaria-si se nos permite la expresión- que destila la introducción, en la que se propone al lector explorar un laberinto literario, pero firmemente asido a conceptos familiares que le remitirán a sus propios saberes.

\section{TEXTOS ANTOLOGADOS}

Los textos, como hemos apuntado más arriba, se organizan en torno a los tres grandes géneros literarios: narrativa, poesía y teatro. Y tres propinas: una, de excelentes textos sobre el propio hecho de escribir, otra sobre cine y otra sobre imágenes. En la narrativa, y casi a modo de declaración de principios, el Quijote abre paso a otras parodias de novela de caballería, como pueden ser las de Tolkien o Calvino. De aquí pasamos a las relaciones entre cuento popular y cuento literario, $\mathrm{o}$, más precisamente, a las reescrituras contemporáneas de los cuentos populares: de Monzó a Coover o de Finn Garner a Mrözeck. Sigue una espléndida selección de "miniparodias" (Monterroso, Llorenç Villalonga, etc.), y otro espacio dedicado a la greguería y al relato de género. En el apartado de poesía encontramos textos de L1. A. Baulenas, Gloria Fuertes o A.V. Estellés, pero también de Lope o Quevedo o del rector de Vallfogona. En el de teatro, auténticos clásicos de la parodia (Pitarra, Rusiñol, Muñoz Seca) así como autores cuyas propuestas teatrales presentan una mayor complejidad, como Valle Inclán o Benet i Jornet. Por si fuera poco, nos quedan aún las tres propinas: en "Va de tot una mica" encontramos una selección espléndida de textos metaliterarios: una parodia del propio hecho de escribir. Recomendamos vivamente la lectura de los fragmentos de Calders, de Jordi Viader o de Xavier Moret para comprender la visión crítica aplicada, no a un tema o a un género, $\mathrm{o}$ a una obra, sino a la propia materia de que está hecha la literatura. Un verdadero juego de espejos. Igual interés tienen los capítulos dirigidos al cine o a la imagen. Estos tres apéndices son de tal riqueza de sugerencia, que el lector se pregunta si no se podría haber hecho un segundo libro con estas "propinas".

Que conste que no mencionamos, ni mucho menos, todos los autores antologados, sino tan sólo unos cuantos.Porque la cantidad de textos es, sencilla- 
mente, apabullante. Uno no puede menos que quitarse el sombrero ante el trabajo realizado por M. Dolors Madrenas. La autora es una "antóloga voraz", que no se ha contentado con unos pocos ejemplos para ilustrar sus premisas, sino que ha ofrecido un número de textos que supera con creces las expectativas. $\mathrm{Ni}$ la autora -ni el lector- descansan; siempre hay un texto más que amplía un concepto o matiza una visión. Pero no sólo hablamos de cantidad, sino de calidad: calidad en los criterios de selección, muy bien determinados y bien orientados a presentar un mosaico a lo largo y a lo ancho de la literatura. A lo largo, desde el XVI a nuestros días, aunque con predominio de los textos contemporáneos. A lo ancho, textos de diferentes culturas: catalana, castellana, extranjera.

Pero es preciso destacar que D. Madrenas no divide los textos en función de lenguas. Literatura catalana y castellana $-y$ las correspondientes extranjeras traducidas a una u otra lengua- se agrupan por razones de género, de tema o de intención, consiguiendo una verdadero ejercicio de literatura comparada en dos lenguas que coexisten en un mismo espacio geográfico. Esto nos lleva a reflexionar sobre cómo el enfoque temático, o el genérico, pueden ayudar a trascender el modelo unilingüe y unicultural para trabajar desde criterios más amplios, -y más adecuados- sobre el fenómeno literario. Ver que un autor hispano parodia a La Fontaine o a Kafka da una idea de los constantes trasvases de temas, topos, escuelas o géneros entre diversas culturas y ayuda a comprender el funcionamiento de la literatura. Desde esta perspectiva, es interesante ver los ejemplos en que un autor catalán ha tenido como modelo un texto -o un tema, o un género, etc.- de la poesía castellana. Por ejemplo, el poema que gira en torno a las églogas garcilasianas, de Vicent Andrés Estellés, o la parodia del culteranismo hecha por el rector de Vallfogona, o la inspiración ramoniana de Sindreu. Además de la gracia o del interés per se, este hecho nos lleva a otra reflexión : cómo estos "modelos consolidados" que han de ser el punto de apoyo de la parodia pasan de la literatura castellana a la catalana, y nunca al revés. No hay que ser un lince de la sociolingüística para saber por qué.

Otro punto interesantes es ver cómo D. Madrenas ha explorado en busca de textos de diferente alcance: desde autores archiconocidos a autores más remotos; desde autores mil veces reeditados a los que casi cayeron en el olvido (ese texto de Joaquín Belda!!!)

Sin embargo, una pequeña objeción referida a la forma en que los textos están dispuestos. Los fragmentos no se presentan siempre independientes, "exentos", sino, en muchos casos, entreverados con las apreciaciones críticas de la autora. Este procedimiento tiene indudables ventajas de coherencia, pero también algún inconveniente: la dificultad del lector en detectar la presencia de los fragmentos, ahogados, en algún caso, por los comentarios críticos. Otra de las desventajas es la falta de titulación y de autor al inicio de los fragmentos: en ocasiones, el lector no puede averiguar qué está leyendo hasta pasadas dos o tres páginas y comprobada la nota a pie de página donde, allí sí, se da la referencia exacta del texto leído. 


\section{PROPUESTAS DE TRABAJO}

Por último cabe comentar las sugerencias de trabajo, o, como la colección las denomina, "Per llegir millor". Efectivamente, cada capítulo ofrece unas posibilidades de explotación de los textos encaminados a diversos propósitos: tal vez uno de los más interesantes sea el de la invitación a la lectura de los textos completos, de los que el fragmento sería una simple muestra, así como de los modelos en que se ha basado el "parodista". Proyecto, pues, de largo alcance, lejos del "cuadernillo de ejercicios", en el que el lector simplemente tiene que ir contestando mecánicamente. Es una auténtica tarea de animación a la lectura y un verdadero plan lector.

Pero además de este propósito, que no es baladí, existen otros que coinciden con los objetivos de la enseñanza de la literatura: los casos en que D. Madrenas propone la búsqueda de datos histórico-literarios que consoliden el esquema diacrónico de la parodia, y, en consecuencia, la situación histórica de los textos. O bien otros en los que se propone descubrir el mecanismo de la parodia. La autora convida a dirigirse al modelo y comprobar cuáles han sido los recursos -temáticos, discursivos, argumentales- que han llevado a subvertir el texto-modelo; en consecuencia, el lector analizará aquí aspectos formales, estructurales y temáticos que le llevarán a profundizar en conceptos literarios. Y por último, algunos en que se pretende aplicar los conocimientos adquiridos a la práctica de la parodias: en consecuencia, también, el alumno se ejercitará como productor de textos paródicos.

Las propuestas son, pues, muy interesantes. Pero tal como hemos comentado cuando nos referíamos al esquema de los textos, de nuevo habría que comentar la dificultad de lectura producida por el exceso tipográfico: negritas, cursivas, textos recuadrados en sombra y otras peculiaridades crean en el lector una cierta sensación de confusión; de no saber a qué texto se refieren las preguntas o, simplemente, de qué texto estamos hablando. Es una lástima que con tan excelentes textos y tan buenas propuestas se cree esta sensación de desorden.

Un desorden que no emana en absoluto de las intenciones de la autora, que nos ofrece un libro coherente, completo y muy interesante. Un libro que, contradiciendo a su título, va completamente en serio. Un estupendo trabajo.

Ana DíAz-Plaja Universitat de Barcelona 